\title{
Resgate de arquivos: o caso Edgard Leuenroth
}

\author{
Walnice Nogueira Galvão ${ }^{1}$
}

\section{Resumo}

O resgate de arquivos, sobretudo da memória política ameaçada por ditaduras ou regimes totalitários, é sempre tarefa das mais urgentes. O salvamento do Arquivo Edgar Leuenroth, da Universidade Estadual de Campinas, hoje famoso e considerado o mais valioso conjunto de documentos do movimento operário na fase de implantação do sindicalismo no Brasil, envolveu muitos intelectuais e instituições. Vale a pena acompanhar o raciocínio e o percurso de vida daqueles que perceberam a importância desse acervo e se empenharam em preservá-lo.

Palavras-chave

Arquivo Edgar Leuenroth - Unicamp, movimento operário, sindicalismo, acervos documentais.

Recebido em 11 de novembro de 2011

Aprovado em 8 de dezembro de 2011

1 Professora Emérita da FFLCH-USP. Crítica literária e cultural, é estudiosa das obras de João Guimarães Rosa e Euclides da Cunha. Recebeu em 2009 o Prêmio da Biblioteca Nacional pelo livro Minima mímica: Ensaios sobre Guimarães Rosa (Companhia das Letras, 2009) e, em 2010, publicou Euclidiana: Ensaios sobre Euclides da Cunha (Companhia das Letras, 2009), ganhador de Prêmio da Academia Brasileira de Letras. E-mail: wngalvao@uol.com.br 


\title{
Recovering Archives: the Case of Edgard Leuenroth
}

\author{
Walnice Nogueira Galvão
}

\section{Abstract}

Archival recovery, especially of memory threatened by dictatorships or totalitarian regimes, is always a pressing task. The recovery of the Edgar Leuenroth archive at the Universidade Estadual de Campinas, considered the most valuable set of documents on the workers' movement during its unionization phase, involved many intellectuals and institutions. To accompany the reasoning and life-paths of those who realized the sheer importance of this archive and endeavored to preserve it is a worthwhile pursuit.

\section{Keywords}

Edgar Leuenroth Archive - Unicamp, workers' movement, unionism, intellectuals' archives. 


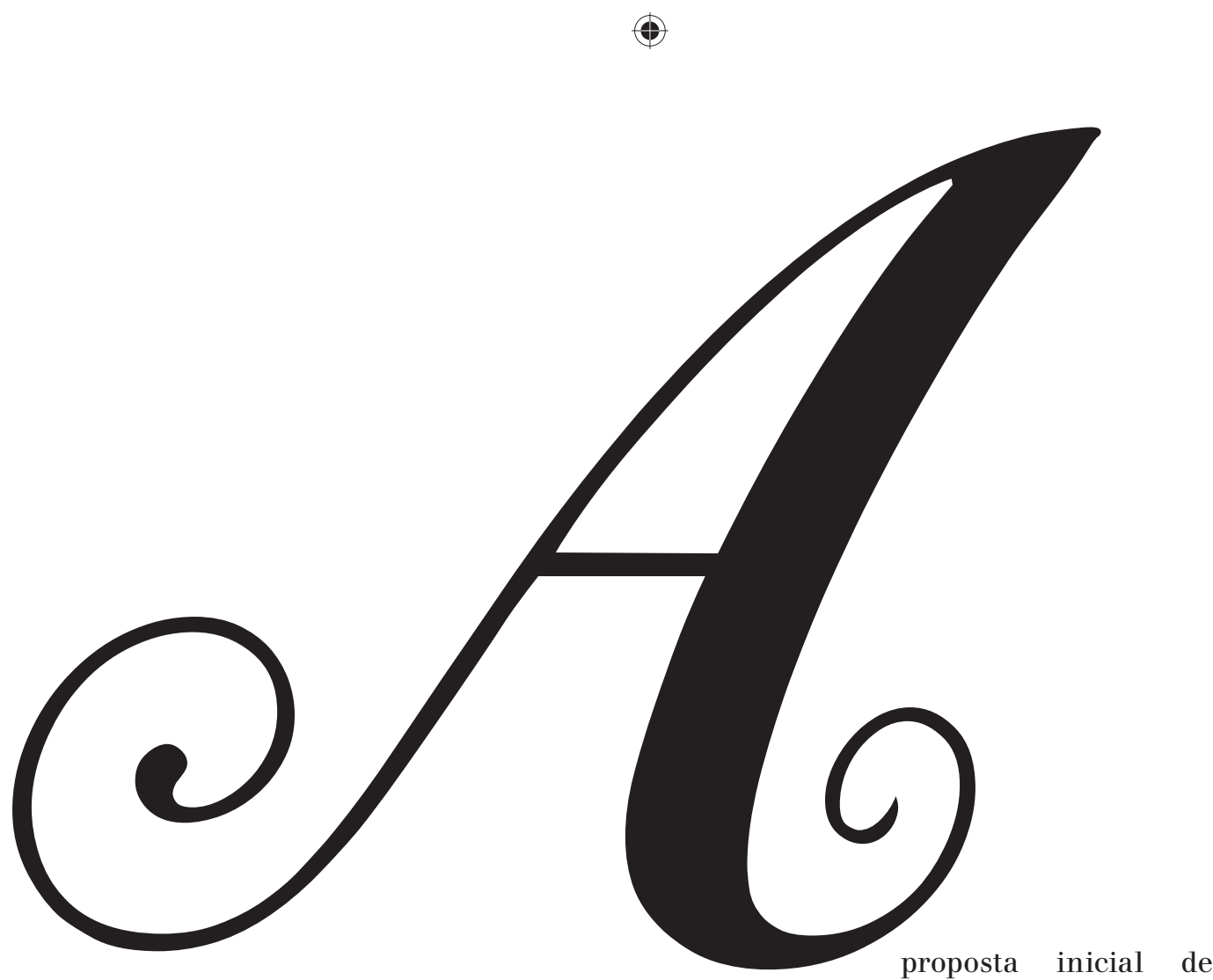

aquisição dos papéis pessoais de Edgard Leuenroth, como se sabe, visava a preservar a memória do período de formação do proletariado no Brasil, meticulosamente documentada pelo líder da primeira greve geral em 1917. Um tal alvo já era relevante por si só, colocando nosso país no reduzido cenáculo dos principais centros de documentação operária, inclusive brasileira, em que se destacam o Instituto Internacional de História Social de Amsterdam e mais o Feltrinelli e o Gramsci, ambos na Itália. Posteriormente à fundação do arquivo que leva o nome do grande militante na Universidade Estadual de Campinas (Unicamp) em 1974, à medida que novas doações foram chegando, os interesses se estenderiam aos movimentos sociais. Foi assim que veio a abrigar materiais relativos ao movimento estudantil, ao homossexual, ao feminista. Entre outros campos dos mais dignos de nota destaca-se o Fundo Ibope, que engloba meio século de pesquisas de opinião (1940-1990). Tem-se especializado no Brasil republicano e na ditadura militar, no âmbito dos quais recebeu os materiais do projeto Brasil Nunca Mais, que reúne testemunhos sobre a tortura. Ao todo, conta hoje com 101 fundos e coleções.

Sem dúvida, uma das mais importantes missões culturais em que se possa pensar é a de resgatar bibliotecas e papéis ameaçados de destruição. E não só por causas aleatórias ou catástrofes naturais; mas, especialmente, durante a vigência de regimes totalitários, marcados tanto pelo obscurantismo quanto pela perseguição ao pensamento e às

revista ieb $n_{54} 20 I 2$ set./mar. p. 2I-30 
coisas do espírito. No pós-64, o salvamento dos arquivos de intelectuais de esquerda visados pela ditadura tornou-se tarefa de primeira urgência. Alguns acervos foram irremediavelmente perdidos, como por exemplo o de Astrojildo Pereira - respeitado intelectual que foi um dos nove fundadores do Partido Comunista e seu primeiro secretário-geral-, apreendido e dispersado pela repressão $0^{2}$ : livros de sua biblioteca foram encontrados em alfarrabistas. Por volta dessa época, certas coleções sobreviveram graças ao interesse de colegas norte-americanos: salvas, felizmente, mas infelizmente expatriadas. E consta que também estavam tentando comprar o arquivo de Leuenroth, pelo qual ofereceram 100 mil dólares, por pouco não tendo levado a melhor.

Vamos aqui rememorar as circunstâncias em que os papéis do ilustre anarquista foram parar na Unicamp. Sabemos o quanto foi decisiva a iniciativa dos professores da casa Michael M. Hall e Paulo Sérgio Pinheiro, com o apoio de Manoel Tosta Berlinck, a partir de uma ideia de constituição de arquivo pregada por Fausto Castilho. Esses nomes ficariam perpetuamente ligados ao feito, empenhando-se junto ao reitor Zeferino Vaz, que encampou a causa. Mais tarde, Marco Aurélio Garcia, regressando do exterior, dirigiria por muitos anos o Arquivo Edgar Leuenroth, de que foi propriamente o consolidador enquanto responsável pelo maior projeto apresentado à Fapesp, destinado a sua organização ${ }^{5}$. Ficaria célebre sua máxima quando consultado se valia ou não a pena integrar mais uma doação: "O céu é o limite".

Sabemos menos dos de fora da casa.

É destes que trataremos aqui. Quando familiares de Leuenroth, na pessoa de seu filho Germinal, entraram em contacto com Azis Simão para consultá-lo sobre o salvamento, este procurou Antonio Candido para associá-lo ao projeto. Leuenroth morrera em 1968, justamente o ano do AI-5, que fecharia o regime e instituiria o terror de Estado. Seu espólio, depositado num galpão no Brás e conhecido de Michael M. Hall e Paulo Sérgio Pinheiro, corria portanto perigo, e toda a operação de resgate seria feita na clandestinidade, durante o mais negro período sob o poder das fardas, o governo Médici. A preocupação era tanta que se temia a possibilidade de um atentado a bomba contra o galpão. Assim que chegou à Unicamp o riquíssimo material - o mais

2 Restaria alguma coisa para o Instituto que leva seu nome.

3 Ver lista e conteúdo de todos os projetos no site da Unicamp/AEL. O primeiro e marco fundador (1973-1974) é o Projeto de Aquisição apresentado à Fapesp, tendo por responsável Manoel Tosta Berlinck. Os avalistas foram Fernando Novais, Ítalo Tronca, Paulo Sérgio de Moraes Sarmento Pinheiro e José Roberto do Amaral Lapa. O recibo da importância de Cr\$ 40.0oo,oo foi assinado por Germinal Leuenroth. 
importante do país - trataram de microfilmar tudo, guardando uma cópia nos cofres do Citibank e depositando outra no mencionado Instituto em Amsterdam. A relevância das coleções já era conhecida em círculos seletos da esquerda, e Caio Prado Jr., que cruzara caminhos com Leuenroth nos mesmos cárceres, embora um fosse comunista e o outro anarquista, lhe propusera providenciar abrigo e manutenção por sua conta, sem que a proposta fosse aceita ${ }^{4}$.

Azis Simão e Antonio Candido, patronos da proeza e autores do parecer que acompanhou o Projeto de Aquisição pela Unicamp, manifestaram-se em texto admirável nos circunlóquios impostos pela necessidade de armar uma cortina de fumaça. Tanto que o dono do arquivo é mencionado como "humanista" e não como anarquista, o interesse de seus papéis é atribuído a uma generalidade histórica e jamais é mencionada a classe operária ou a formação do proletariado. Assim reza o ofício dirigido ao diretor do Instituto de Filosofia e Ciências Humanas (IFCH), Manoel Tosta Berlinck, membro da conspiração e disposto a ajudar:

Como conhecedores de longa data do Arquivo de Edgard Leuenroth, sabemos que se trata de um dos acervos mais preciosos que há no Brasil para estudo de nossa vida política e social desde o começo do século.

Edgard Leuenroth, uma das mais belas figuras de humanista de nosso panorama cultural, reuniu pacientemente durante toda a vida um acervo realmente monumental de documentos impressos, como jornais, folhetos, boletins, etc., não encontráveis noutra parte, através dos quais é possível levantar de maneira cabal alguns aspectos de nossa história recente, que de outro modo ficarão sem o devido apoio documentário.

Há já algum tempo, vários intelectuais têm manifestado apreensão pelo destino deste material, cuja dispersão importaria em perda irreparável para a documentação histórica de nosso país. Seria do maior interesse que uma instituição do porte da Universidade de Campinas pudesse mantê-lo íntegro, como fonte de pesquisas no campo das Ciências Humanas.

Assinam Azis Simão e A. C. de Mello e Souza ${ }^{5}$. Velhos amigos e colegas na militância socialista, foram ambos assistentes de Fernando

4. Antonio Candido, comunicação à autora, 22 jul. 2010.

5 O cotejo do datiloscrito atesta proveniência da máquina de escrever de Antonio Candido à época.

revista ieb $n_{54} 2012$ set./mar. p. 21-30 
Azevedo, na cadeira de Sociologia da Faculdade de Filosofia, Ciências e Letras da USP.

Azis Simão foi pioneiro no estudo do voto operário, sendo autor do primeiro trabalho universitário de maior envergadura sobre formação do proletariado, Sindicato e Estado ${ }^{6}$, um clássico, tese de livre-docência em Sociologia defendida naquela Faculdade. Militaria à esquerda a vida inteira, primeiro como anarquista, quando fez amizade com Leuenroth, depois no Partido Socialista, onde se inscreveu em 1933, ano da fundação. Participaria da famosa revista de esquerda Problemas e integraria os vários avatares que seu partido assumiu ao sabor das idas e vindas da repressão, em duas ditaduras.

Professor de Sociologia a partir de 1950 na mesma casa, manteve por toda a vida a militância e o convívio na área operária - que soube levar para a área universitária -, inspirando dezenas de teses, tão fértil se revelaria o caminho por ele desbravado. Transferiu, o que é raro, sua genuína adesão à causa proletária para seus trabalhos científicos. Como se sabe, aquela que viria a se chamar "escola paulista de Sociologia" privilegiava a pesquisa de campo e de documentos.

Sua duradoura amizade com Leuenroth começou nas circunstâncias que relato a seguir. Com dezessete anos e membro de uma geração extremamente "literária", ou seja, que lia muita literatura mundial - tanto ficção quanto poesia - fosse qual fosse sua especialidade, fora trabalhar no suplemento literário do São Paulo Jornal. Intitulado "Página Verde e Amarela", o suplemento era dirigido por Menotti Del Picchia e Cassiano Ricardo, poetas integrantes da elite do Modernismo e criadores do movimento chamado Verdeamarelismo, derivação do Modernismo que guinaria para a direita. Outros, inclusive Oswald de Andrade, que entraria para o Partido Comunista em 1930, guinariam para a esquerda, no divisor de águas que foi, aqui e no mundo, a crise de 1929.

Um colega de jornal levou Azis Simão para a celebração do aniversário da União dos Trabalhadores Gráficos (UTG), de que era médico seu irmão Aniz Simão, e foi lá que ele e nosso anarquista, tipógrafo, se conheceram e se tornaram amigos. $\mathrm{O}$ anarquista, trinta anos mais velho que Azis, pois nascera em 1881, já era, a essa altura, um renomado militante. Como bom anarquista, era contra qualquer organização, seja propriedade, Estado, sindicato. Ele mesmo, no fundo, era um anarcossindicalista e, no velho espírito do ativismo libertário, considerava-se aliado

6 SIMÃO, A. Sindicato e Estado: Suas relações na formação do proletariado de São Paulo. São Paulo: Dominus, 1966 e São Paulo: Ática, 1981. 
dos propriamente sindicalistas, sendo companheiro leal dos socialistas, trotskistas e comunistas dissidentes.

Azis Simão, nessa fase de sua vida, nos anos 1930, portanto, praticava a boêmia modernista, e se tornara amigo chegado de Oswald e de Pagu, criadores do jornal de militância O Homem do Povo, que Azis frequentou e ao qual deu seu apoio. O jornal teria curta vida porque, hostilizado pelos estudantes da Faculdade de Direito do Largo de São Francisco, seria objeto de tentativas de depredação e empastelamento, acabando por ser fechado pela polícia (que, naturalmente, visava a proteger os jornalistas...).

Ele próprio rememoraria amiúde que frequentava cafés ${ }^{7}$, sendo ali que a camaradagem se desenvolvia. Lugar de convivência intelectual, parte do estilo de vida urbano ocidental nas grandes cidades do mundo, o "café sentado", como era chamado, seria substituído pela introdução do "café expresso", tomado de pé no balcão. É reconfortante saber que isso aconteceu em São Paulo mas não no Rio de Janeiro e nas capitais europeias, onde a primeira modalidade, que dá direito a várias horas de posse de uma mesa e à leitura dos jornais do dia mediante o consumo de um mero cafezinho, continua uma instituição. Votado à convivência com os amigos, é portanto um espaço consagrado de sociabilidade, como se pode verificar nos pubs ingleses e nos bistrôs franceses ainda hoje.

Vamos encontrar Azis Simão em 1934 como professor da Escola Proletária Paulista, cujos cursos noturnos gratuitos, mantidos pelos sindicatos, eram destinados à educação de adultos. Mas a repressão que se seguiu ao levante comunista de 1935 atingiu todas as facções da esquerda e a escola foi fechada.

Dali, Azis transitaria para a recém-fundada Faculdade de Filosofia, Ciências e Letras da USP, primeiro como ouvinte e depois como aluno. Ainda nesse decênio participaria da resistência à ditadura Vargas, entrando, ao fim desta, primeiro para a União Democrática Socialista (UDS) e depois para a Esquerda Democrática, frente ampla que ia do centro à esquerda. Em seguida, os socialistas constituiriam o novo Partido Socialista Brasileiro, enquanto os do centro iriam para a União Democrática Nacional (UDN). Azis tornaria a se inscrever e ali continuaria até o partido ser novamente fechado pelo golpe de 1964. Estudaria

7 Entrevista a José Albertino Rodrigues, Portal IBCT/Canal Ciência; ver <http:// Www.canalciencia.ibict.br>; SIMÃO, A. Os anarquistas: duas gerações distanciadas, Tempo Social, revista do Departamento de Sociologia da USP, 1989. CANDIDO, Antonio. O companheiro Azis Simão. In:__ Recortes. São Paulo: Companhia das Letras, 1993. CARVALHO, V. M. de; COSTA, V. R. da (orgs.). São Paulo: Cientistas do Brasil. SBPC, 1998. 
Ciências Sociais e terminaria por definir-se profissionalmente como sociólogo e professor daquela casa.

Logo começaria a investigar o proletariado com pesquisa de campo, inicialmente concentrando-se em voto e consciência de classe, algo inédito até então, e terminaria por fixar-se no tema de seu trabalho maior, Sindicato e Estado, sobre a formação do proletariado paulista.

Quanto a Antonio Candido, além de tudo o que realizou em várias áreas, gostaria de lembrar aqui o autor de Teresina etc. ${ }^{8}$ Também se ligaria a Leuenroth, mas por outros caminhos. Antes de mudar-se para São Paulo, quando ainda vivia com os pais em Poços de Caldas, sua mãe se tornara grande amiga de uma vizinha, D. Teresina Carini Rochi. Esta, uma socialista histórica, convivera em São Paulo com os principais pioneiros da militância de esquerda na fase de formação da classe operária. Pode-se aquilatar o quanto D. Teresina impressionou o jovem, que escreveria várias vezes sobre ela, começando já em seu segundo livro, $O$ observador literário (1959). A notar que a mais recente edição deste (Ouro sobre Azul, 2004) não traz o texto, avançando a explicação de que tinha sido absorvido em Teresina etc. Acabaria por dedicar-lhe todo um livro. Era ela uma socialista revolucionária de fortes convicções, que o fez meditar não só sobre as ideias mas também sobre a existência do "ser socialista".

Nesse livro, o autor carinhosamente estudou Teresina, ampliando o círculo de suas indagações até englobar a geração de militantes, sobretudo italianos, a que ela pertenceu. Reconstituiu, com base no que dela ouviu e em seus papéis, a aldeia em que nasceu e o castelo à sombra do qual foi criada, em Fontanellato, perto de Parma, na Itália, fazendo uma análise das pinturas murais do castelo no intento de restaurar seu ambiente na juventude. E através dela tomaria conhecimento de toda essa constelação, inclusive Leuenroth.

A propósito do círculo de italianos militantes de esquerda amigos de Teresina, pode-se falar no sindicalismo revolucionário ítalo-paulista. ${ }^{9}$ Esse círculo destacou-se em São Paulo no período, como se sabe marcado por oriundos da península. O destino de quatro de seus mais queridos camaradas é exemplar.

Quase todos eram foragidos da Itália, perseguidos por suas posições políticas. São eles Alcibiade Bertolotti, Antonio Piccarolo, Alceste De Ambris e Edmondo Rossoni. Representantes de várias tendências,

8 CANDIDO, Antonio. Teresina etc. 3. ed. Rio de Janeiro: Ouro sobre Azul, 2007.

9 TOLEDO, Edilene. Anarquismo e sindicalismo revolucionário - Trabalhadores e militantes em São Paulo na Primeira República. São Paulo: Fundação Perseu Abramo, 2004. 
vivendo e militando no Brasil mas atraídos em maior ou menor grau pela sereia do fascismo e de Mussolini, têm seu percurso definido por uma decisão que não era fácil de tomar, sobretudo em vista dos tons populares e obreiristas que o fascismo italiano assumiu no início.

O primeiro, Bertolotti, socialista reformista, fundou e dirigiu por longo tempo o jornal Avanti!, que mantinha em São Paulo o mesmo título do órgão oficial do Partido Socialista italiano. Combativo, criou livrarias, partidos efêmeros e uma liga de frenteampla de esquerda. Trabalhava em engenharia, que era a sua profissão. E nunca deixou de ser antifascista.

O segundo, Piccarolo, também socialista reformista mas menos militante, embora integrasse o grupo do jornal Avanti!, teve vasta circulação social e prestígio nos meios liberais de São Paulo, tanto intelectuais quanto mundanos. Frequentava o salão da Vila Kyrial de Freitas Valle e fazia conferências na Sociedade de Cultura Artística. Tradutor de Dom Casmurro para o italiano, capitaneou a criação de uma Faculdade Paulista de Letras e Filosofia, que não durou muito, indo depois para a novel Faculdade de Filosofia da USP e para a Escola Livre de Sociologia e Política.

De Ambris, também do grupo do jornal e de ideais políticos próximos, detinha o privilégio de ter um retrato seu pendurado na parede da casa de D. Teresina. Em reprodução, é como o vemos com seu ar de personagem de ópera do Risorgimento, todo em cores escuras, chapéu preto, tremendos bigodes encerados e retorcidos nas pontas. Também ele, como Bertolotti, era foragido político que fora obrigado a deixar a terra natal. Tendo voltado à Itália no primeiro decênio do século, envolveu-se em greves e ativismo político que o levaram a novamente se exilar no Brasil. Mas pouco depois estava outra vez na Europa, participando em posição destacada como Capo di Cabinetto na aventura de Gabriele D'Annunzio no Fiume e seu golpe de um governo paralelo, logo desarticulado por Mussolini. Foi companheiro de viagem dos fascistas nessa fase, $\mathrm{e}$ candidato derrotado a deputado, mas acabou se incompatibilizando com eles, desterrando-se mais uma vez, só que na França. Ali liderou campanhas antifascistas até morrer e escreveu um livro contra Mussolini.

Entre esses italianos amigos próximos de D. Teresina, o de trajetória mais retumbante é Edmondo Rossoni. Eram eles sindicalistas revolucionários, fossem mais ou fossem menos reformistas, mas este se destacava por ser o mais aguerrido de todos. De ardente petroleiro libertário que era, panfletário e orador de porta de fábrica, a tal ponto que seria oficialmente banido do Brasil, passaria a fascista entusiasmado, fazendo uma bela carreira depois de voltar à Itália, onde, aproveitando sua experiência em nosso país, organizaria o trabalhismo fascista e o corporativismo. Seria nada menos que ministro de Mussolini, e mais de uma vez.

revista ieb $n_{54} 2012$ set./mar. p. 2I-30 
Intrigada com as notícias que lhe chegavam de seu antigo companheiro de lutas, D. Teresina escreveu-lhe uma carta para apurar a quantas andava. Recebeu (e guardou) uma resposta de Rossoni que explicitava tudo e ainda fazia propaganda fascista. Fora de si, mandou-lhe um bilhete lacônico, cortando relações e dizendo apenas: Sei un cane.

Quanto ao velho amigo anarquista Edgard Leuenroth, D. Teresina privilegiou as relações entre ambos até sua morte. Antonio Candido o menciona em vários trabalhos, impressionado com sua intransigência política ligada a enorme cordialidade e cortesia. E, ao escrever um comentário sobre as várias acepções do vocábulo "anarquista" e os diferentes tipos de ativista que encobriam (aliás, para um número especial da revista Remate de Males da Unicamp ${ }^{10}$ ), aproveita para narrar um episódio de que foi testemunha.

Estava um grupo reunido na sede do Partido Socialista, em 1948, para comemorar o Primeiro de Maio, numa fase negra para a esquerda, quando qualquer celebração da data estava proibida. Isso se deu após a decretação da ilegalidade do Partido Comunista e a cassação do mandato dos eleitos no pleito que se seguiu à queda da ditadura Vargas. Leuenroth compareceu, pediu a palavra e explicou sua posição, dizendo que, sendo libertário, postava-se contra qualquer partido e contra eleições, mas que, numa data como aquela, sentia-se impelido a procurar a companhia de camaradas de luta, mesmo com essas discordâncias que lealmente queria expor.

Essa era a têmpera dos velhos militantes, e desse modo foi natural que dois deles, já de outra geração, Azis Simão e Antonio Candido, patrocinassem a ida para a Unicamp dos papéis de alguém que respeitavam e admiravam. Tentei costurar os retalhos dessa passagem, para mostrar por que vias ela se fez. De modo que, desde a pessoa de Leuenroth através de sua amizade com aqueles dois que se tornariam mais conhecidos pela produção intelectual, foi imperativo o encaminhamento dessa suma de experiências da esquerda para o arquivo que leva seu nome e guarda a curadoria do acervo na Unicamp.

10 "Sobre a retidão", recolhido em seu livro Recortes. op. cit.

revista ieb $\quad n_{54} 2012$ set./mar. p. 2I-30 